\title{
Why Hypertensive Patients are Considered Today a Risk Group for COVID- 19?
}

\author{
Huang Wei Ling* \\ Infectious Diseases, General Practice, Nutrition, Acupuncture and Pain Management, Medical Acupuncture and Pain \\ Management Clinic, Franca, São Paulo, Brazil
}

*Corresponding author: Huang Wei Ling, Infectious Diseases, General Practice, Nutrition, Acupuncture and Pain Management, Medical Acupuncture and Pain Management Clinic, Franca, São Paulo, Brazil, Rua Homero Pacheco Alves, 1929, Franca, São Paulo, Brazil

\section{ARTICLE INFO}

Received: 蔧 June 15, 2021

Published: 㗀 June 23, 2021

\section{ABSTRACT}

Citation: Huang Wei Ling. Why Hypertensive Patients are Considered Today a Risk Group for COVID- 19?. Biomed J Sci \& Tech Res 36(4)-2021. BJSTR. MS.ID.005896.

\section{Editorial}

The author always found strange to know that hypertensive patients according to Western medicines were considered risk groups until this pandemic arrived [1]. But according to Western medicine, what they say is that, for example, in a study written by Fang et al. [2], in an article entitled Are patients with hypertension and diabetes mellitus at increased risk for COVID-19 infection? they are saying that hypertensive patients are high risks due to the to the angiotensin-converting enzyme 2 (ACE 2) where the SARS$\mathrm{CoV}-2$ bind the target cells (and they say that hypertensive patients are also treated by ACE inhibitor, with results in an upregulation of ACE2) [2]. But not all hypertensive patients use angiotensin converting inhibitor and why they still are considered high risks for COVID-19?

The author is a medical doctor with 6 specialties and she had an opportunity to study Western medicine and Eastern medicine during the 29 years of medical experience. In 2021, she published an article entitled Energy Alterations and Chakras' Energy Deficiencies and Propensity to SARS-CoV-2 Infection, where she is demonstrating a research she did in Brazil analyzing the results of 1000 patients chakras' energy centers measurement and what she discovered was that more than $90 \%$ of her patients do not have internal energy in any chakras' energy centers, that corresponds to the five massive organs (Liver, Heart, Spleen, Lung, Kidney) of traditional Chinese medicine. In this research, she is demonstrating that, independently of the diagnosis of the patient, if they have anxiety, depression, panic syndrome, knee pain, low back pain, headache, etc...they all have chakras' energy centers deficient in energy. Each internal massive organ is responsible for the production of one internal energy for maintenance of health of the human body (Yin, Yang, Qi and Blood) and the imbalances of these energies are responsible for the formation of diseases in the leaf level of the tree, showed in many articles written by the author [3-6].

In the study Energy Alterations as the Underlying Cause of Primary Hypertension? the author presented at the International Conference on Global Heart Congress that was held in July 0810, 2019 in Paris, France and in the $2^{\text {nd }}$ International Conclave on Hypertension and Healthcare that was held in Tokyo, Japan during April 19-20, 2021. In this study she is showing that all hypertensive patients have in common chakras' energy deficiency and according to Chinese medicine, the energy imbalances that can lead to hypertension is retention of Heat in the Liver meridian (first chakra), energy imbalances in the Kidney meridian (second chakra) and alterations in the Spleen energy meridian (fifth chakra) $[4,7,8]$.

Nowadays, the patients that is being sick by COVID-19 is not only high risks patients but all patients that has no history of comorbidities are all being sick or even dying of this disease. We realize that not only patients with comorbidities such as diabetes, high blood pressure, patient with a history of myocardial infarction, stroke, cancer, but all the other patients who were also not at this 
group of risks are having COVID-19 and sometimes are dying because of it. In an article written by the author (2021) entitled Is the Medication used in Intubation of Patients with Covid-19 Affecting the Outcome of the Patient's Treatment? the author is questioning in this article if really the patients with COVID-19 are dying due to the virus or due to the use of highly concentrated medications, recommended for the use of all patients nowadays, in many protocols. In the article written by Brandon Ng et al. [10] entitled Medication use during COVID-19: Review of recent evidence, the author said in their review, they found that medications such as nonsteroidal anti-inflammatory drugs, angiotensin-converting enzyme inhibitors, angiotensin receptors blockers, hydroxychloroquine and chloroquine, lopinavir-ritonavir are some drugs used in some studies and considerable controversy has caused because limited clinical evidence supports their use implicating in the safety of the patient and it is a problem in the public health $[9,10]$.

In an article published by the author (2021) entitled Are We Vaccinating Immunocompetent or Immunocompromised People for COVID 19? she concluded that most patients who are receiving the vaccine nowadays are characterized as immunocompromised and not immunocompetent [11]. The lack of understanding of the meaning of energy changes by the Western medical doctors is mainly due to the changes caused by Flexner's report in 1913, where changed the form of teaching medical doctors and implemented new norms for the functioning of the medical schools in three main continents of our planet (Americas, Europe and Asia), In this reformulation, all medical institutions that were not considered scientific, such as the ones who works with natural medicine and herbal medicine, homeopathy, osteopathy and chiropractic needs to close their doors and only $20 \%$ of these schools remains open $[12,13]$.

This incomplete way of see the patient, only by the matter part and not understanding that human body is also made by energy, is leading to many problems nowadays in doing early diagnosis and early treatment. Western medicine's diagnosis is usually very late, when there is laboratory alteration in the phase four or five only, when the physician needs to do the diagnosis in the early phase, when there are energy alterations and the laboratorial exams are still normal [4-6]. Nowadays, the negative effects of this kind of implantation are going through us when facing this COVID-19 pandemic, where all alterations are only in the energy level, invisible by the naked eyes [3].

The majority of medical doctors nowadays have been trained to see only part of the matter and are unaware of the energy changes that patients have and that are the cause of most diseases today and all difficulties to control this pandemic due to the fact that they are not acting in the cause of the problem, that is this energy deficiency, caused by the exposition to the electromagnetic waves, after the implantation of the $5 \mathrm{G}$ technology, leading to this immunosuppression in quite all patients in this world, as this kind of waves are in all countries and houses in these modern days $[3,11]$. The use of medications considered scientific by medicine nowadays, being highly concentrated medications, has caused a very important damage to the vital energy of our patients nowadays and the drugs of choice to use in every treatment are the highly diluted medications such as homeopathies, as the author will present this subject in the $3^{\text {rd }}$ International Conference on Infectious Diseases, that will be held on August 06 - 07, 2021 [14].

Therefore, through rules that in the past were considered unscientific medications, homeopathies are now the drugs of choice for the treatment of our patients today due to the change in the energy pattern of our world population work. These thoughts were published by the author (2021) in an article entitled Is the Population in the World the Same as in the Past? [15]. Therefore, changes in the medical curriculum must be done in the entire world, because the mistakes made in the past implanting the type of teaching medical doctors in all medical faculties only looking at the matter point of view and not understanding that there is another point that human being is made that is very important to understand, are reflecting on the physician's attitudes today. After more than 100 years of implementation of this reform, we have to rethink that all reasoning has not been very well formulated in medical schools, concerning the formation of diseases in the human being, so using a holistic view of the human body and not looking only into the matter part, our future doctors can learn to prescribe drugs according to the new type of patients that we have nowadays, to help improve the vital energy of our patients and thus achieve health $[9,15]$.

Currently, doctors who are graduating are learning in their medical schools only to prescribe medicines that are causing harm to the vital energy, that the author showed in her research (2021) in the article Energy Alterations and Chakras' Energy Deficiencies and Propensity to SARS-CoV-2 Infection. According to the publication written by the author (2021) entitled, Is the Population in the World the Same as in the Past? the author is showing that our population in the world is not the same as in 6 or 7 years ago, when they had energy in the chakras' energy centers and nowadays, they do not have energy in the majority of them $[3,15]$. To finalize this article, the author wants to show that hypertensive patients have chakras' energy deficiency and for this reason it is considered high risks patient when analyzing the energy level of this patients. As the majority of the population are in this same energy pattern [4].

All patients nowadays are considered high risks to acquire COVID-19 if no measures of changing this energy patter will be made such as studying another way of emitting these electromagnetic 
waves to do not cause harm to our body (in the energy level) and start to replenishing the energy of the entire population using highly diluted medications according to the theory Constitutional Homeopathy of the Five Elements Based on Traditional Chinese Medicine, as the author showed in all her articles $[3,15,16]$.

\section{References}

1. Shibata S, Arima H, Asayama K, Hoshide S, Ichihara A, et al. (2020) Hypertension and related diseases in the era of COVID-19: a report from the Japanese Society of Hypertension Task Force on COVID-19. Hypertens Res 43: 1028-1046.

2. Fang L, Karakiulakis G, Roth M (2020) Are patients with hypertension and diabetes mellitus at increased risk for COVID-19 infection? Lancet Respir Med 8(4): e21.

3. Huang Wei Ling (2021) Energy Alterations and Chakras' Energy Deficiencies and Propensity to SARS-CoV-2 Infection. Acta Scientific Microbiology 4(4): 167-196.

4. Huang WL (2019) Energy Alterations as the Underlying Cause of Primary Hypertension? Journal of Nephrology 4(2): 33-44.

5. Huang WL (2019) Why Are Diabetic Patients Still Having Hyperglycemia despite Diet Regulation, Antiglycemic Medication and Insulin? International Journal of Diabetes and Metabolic Disorder 4(2): 1-14.

6. Huang WL (2020) The Importance of Correcting Energy Imbalances in the Prevention and Treatment of Myocardial Infarction. Acta Scientific Medical Sciences 4(6): 20-27.

ISSN: 2574-1241

DOI: 10.26717/BJSTR.2021.36.005896

Huang Wei Ling. Biomed J Sci \& Tech Res

(c) (P) This work is licensed under Creative Commons Attribution 4.0 License

Submission Link: https://biomedres.us/submit-manuscript.php
7. (2019) International Conference on Global Heart Congress, Paris, France.

8. (2021) $2^{\text {nd }}$ International Conclave on Hypertension and Healthcare. Tokyo, Japan.

9. Huang Wei Ling (2021) Is the Medication used in Intubation of Patients with Covid-19 Affecting the Outcome of the Patient's Treatment? Archives of Anesthesiology 4(1): 01-03.

10. Brandon Ng T, Leblanc K, Yeung DF, Teresa SM Tsang (2021) Medication use during COVID-19: Review of recent evidence. Can Fam Physician 67(3): 171-179.

11. Huang WL (2021) Are We Vaccinating Immunocompetent or Immunocompromised People for COVID 19? J Vaccines Res Vaccin 7: 018.

12. Stahnisch F, Verhoef M (2012) The flexner report of 1910 and its impact on complementary and alternative medicine and psychiatry in north america in the 20th century. Evid Based Complement Alternat Med 2012: 647896.

13. Duffy T (2011) The Flexner Report -100 Years Later. Yale J Biol Med 84(3): 269-276.

14. (2021) $3^{\text {rd }}$ International Conference on Infectious Diseases.

15. Huang Wei Ling (2021) Is the Population in the World the Same as in the Past?. Acta Scientific Clinical Case Reports 2(6).

16. Huang WL (2020) Constitutional Homeopathy of the Five Elements based on Traditional Chinese Medicine. Acta Scientific Medical Sciences $4(7): 57-69$

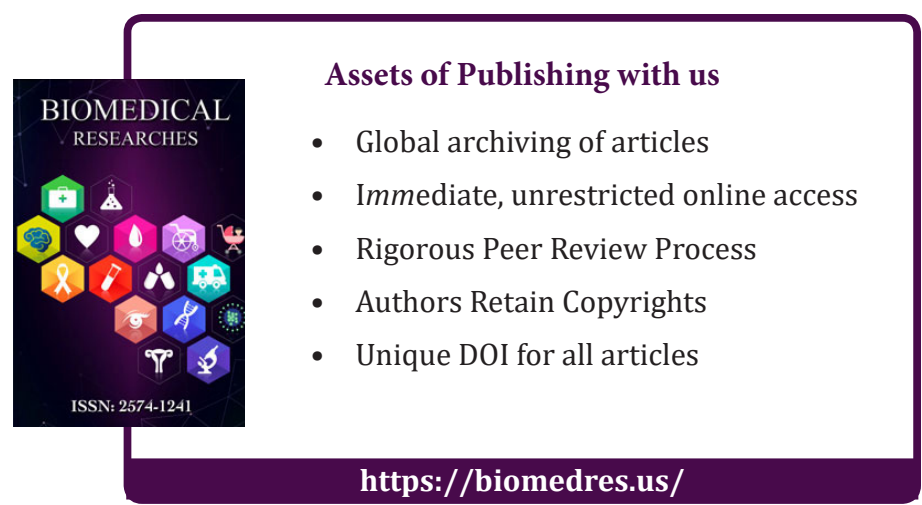

